\title{
PENGARUH IMPOSISI DESAIN KEMASAN TERHADAP KALKULASI HARGA POKOK PRODUKSI
}

\author{
Endang Yuniarti ${ }^{1}$, Emmidia Djonaedi, Delila Mediana \\ Teknik Grafika dan Penerbitan, Politeknik Negeri Jakarta, \\ Jl. Prof. Siwabessy, Kampus baru UI Depok 16245 \\ e-mail: ${ }^{1}$ endang_industri@yahoo.com
}

\begin{abstract}
In the packaging production process, the material that have great influences the price of a packaging is paper material. The arrangement and placement of a product design called imposition in printing platesisdetermines the amount of paper used. If the imposition is not used optimally, the more paper used then the more waste produced. This results in considerable losses for the company. Therefore, this research aims to be low-cost and minimumwaste. The method used is the calculation of production price calculations (HPP) with duplex 350 gsm paper samples. Variations of the imposition used are: Imposition Not Inserts (TS), Insert (S), Join Not Inserts (GTS) and Insert Inserts (GS). This study produces that the imposition of TS produces the lowest waste of $10.87 \%$. While the lowest price is GS imposition, which is $R$ p. 328.00 per package.
\end{abstract}

Key words: packaging, imposition, waste, price

\begin{abstract}
ABSTRAK
Pada proses produksi kemasan, material yang sangat mempengaruhi dalam penentuan harga sebuah kemasan adalah material kertas. Pengaturan dan penempatan tata letak suatu desain produkyang sering disebut imposisi dipakai pada pembuatan pelat cetak sangat menentukan jumlah kertas yang digunakan. Jika imposisi tidak dimanfaatkan secara optimal maka kertas yang digunakan makin banyak dan waste yang dihasilkan akan semakin banyak juga. Hal ini berakibat kerugian yang cukup besar bagi perusahaan. Maka penelitian ini bertujuan untuk murah dan yang menghasilkan waste paling sedikit. Metode yang digunakan adalah perhitungan kalkulasi harga produksi (HPP) dengan sampel kertas dupleks 350 gsm. variasi imposisi yang digunakan, antara lain: Imposisi Tidak Sisip (TS), Sisip (S), Gabung Tidak Sisip (GTS) dan Gabung Sisip (GS). Penelitian ini menghasilkan bahwa imposisi TS menghasilkan sampah (waste) paling rendah sebesar 10,87\%. Sedang yang memiliki harga paling murah adalah imposisi GS, yaitu sebesar Rp. 328,00 per kemasan dengan oplah 10.000 pcs.
\end{abstract}

Kata kunci : kemasan, imposisi, sampah, harga

\section{PENDAHULUAN}

Pada era 2000-an, perusahaan industri kemasan semakin berkembang luas. Pada tahun 2016, nilai bisnis kemasan di Indonesia sudah mencapai US\$ 6,1 juta hingga US\$ 6,2 juta (Wulandari, 2016). Bahkan untuk tahun ini perkembangan industri kemasan di Indonesia diprediksi akan mengalami pertumbuhan sekitar 8-9\%. Meningkatnya perindustrian kemasan di Indonesia didorong karena adanya kebutuhan para konsumen yang tidak bisa lepas dari kemasan. Hal itu yang membuat perusahaan kemasan di Indonesia semakin inovatif dalam membuat kemasan yang diproduksinya, baik dari segi bentuk, desain, maupun ukurannya.

Menurut (Angipora, 2003), kemasan memiliki fungsi yaitu sebagai pembungkus supaya barang didalamnya terlindungi dari kotoran dari luar dan tidak mudah tercemar serta mudah untuk dipindahkan dari satu tempat ke tempat lainnya. Selain itu kemasan 
memiliki fungsi lain yaitu dapat meningkatkan harga jual suatu produk.

Pada proses pembuatan kemasan, banyak material yang dibutuhkan. Begitu pun dengan prosesnya yang tidak singkat. Penentuan harga pada suatu produk kemasan didasari oleh dua faktor utama, yaitu biaya produksi dan biaya non-produksi. Biaya produksi meliputi kertas, tinta, pelat, lem, dan bahan penunjang lainnya. Sedang biaya non-produksi mencakup biaya marketing dan penjualan. Pengaruh harga dari material kertas bisa mencapai lebih dari 50\% dari keseluruhan harga baik materialatupun dari proses produksi. Harga pada material kertas dapat dilihat dari jeniskertas, tebal kertas ataupun besarnya ukuran kertas yang digunakan. Banyaknyajumlah kertas yang digunakan juga mempengaruhi lamanya waktu sebuah produksi.Selain itu untuk menghasilkan waktu produksiyang efektif, maka juga diperlukan perhatian terhadap efisiensi kertas dengan carayang tepat. Dengan adanya efisiensi dalam penggunaan bahan baku kertas,maka secara langsung dapat mengurangi sampah dan perusahaan bisa mendapatkan keuntungan yang lebih besar.

Tujuan dari penelitian ini adalah mendapatkan jenis imposisi yang paling tepat dan menghasilkan waste paling sedikit. Manfaat yang diharapkan adalah dapat meningkatkan efisiensi pada proses pra cetak dan pemakaian kertas saat melakukan produksi (proses cetak). Tahap pertama dalam proses percetakan adalah tahap pra cetak, dimana posisi kemasan ditentukan letaknya dalam satu pelat (ukuran 1 velt) atau yang sering disebut imposisi.

Proses cetak kemasan tidak memiliki perbedaan yang cukup jauh denganproses cetak buku. Perbedaan diantara cetak buku dan cetak kemasan yaitu terletakpada dimensinya. Pada kemasan, dimensi yang digunakan lebih beragam. Selainitu, perbedaan diantara kemasan dan buku dapat terlihat pada bentuk desainnya.Baik buku ataupun kemasan sebelum melalui proses cetak terlebih dahulu akanmelalui proses prepress atau pra cetak. Pada proses prepress, produk yang hendak dicetak akandiimposisi terlebih dahulu.

\section{Imposisi}

Imposisi merupakan pengaturan dan penempatan tata letak suatu desain produk untuk dipakai pada pembuatan pelat cetak (Scheder;1997). Untuk produk buku, proses imposisi harus disesuaikandengan halaman buku. Namun hal ini tidak berlaku untuk kemasan. Pada obyekpenelitian, proses imposisi kemasan dapat dilakukan dengan berbagai cara.Imposisi yang sering digunakan yaitu imposisi gabung dan imposisi sisip. Imposisigabung yaitu imposisi yang terdiri dari berbagai macam produk. Sedangkan imposisi sisip yaitu peletakkan desain kemasan yang dilakukan denganmenyesuaikan setiap sisi pada kemasan. Imposisi ini akan menentukan banyaknya jumlah kertas yang digunakan. Jika imposisi tidak dimanfaatkan secara optimal maka kertas yang digunakan makin banyak dan waste yang dihasilkan akan semakin banyak juga. Hal ini berakibat kerugian yang cukup besar bagi perusahaan. Terdapat beberapa jenis imposisi yang sering digunakan.

\section{Jenis-Jenis Imposisi}

Adapun jenis-jenis imposisi yang digunakan dalam percetakan sebagai berikut:

1. Imposisi tidak sisip, yaitu imposisi yang dilakukan dengan menyesuaikan lembar dan panjang suatu produk kemasan. Imposisi jenis ini biasa digunakan untuk buku. Cara imposisi ini lebih sering digunakan karena lebih mudah diperhitungkan. 


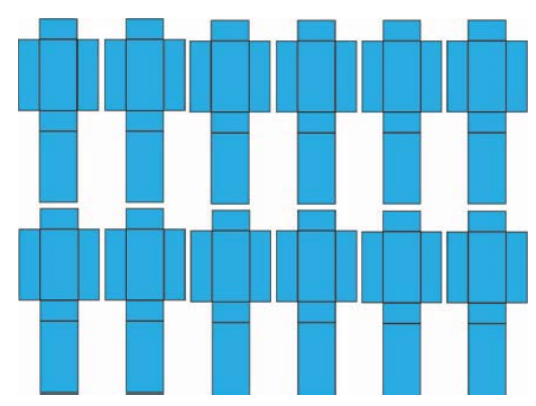

Gambar 1. Imposisi Tidak Sisip (TS)

2. Imposisi sisip, yaitu imposisi yang dilakukan dengan menyesuaikan pada setiap sisi produk kemasan. Tidak seperti buku, kemasan memiliki bentuk yang berbeda disetiap sisinya. Maka dari itu digunakan sistem sisip untuk mengurangi jumlah pemakaian kertas yang terbuang. Meski jumlah up pada imposisi ini dapat memuat lebih banyak dibandingkan imposisi lainnya, namun imposisi ini memiliki kelemahan yaitu pada proses cetak dan proses die cutting lebih sulit untuk mencapai register.

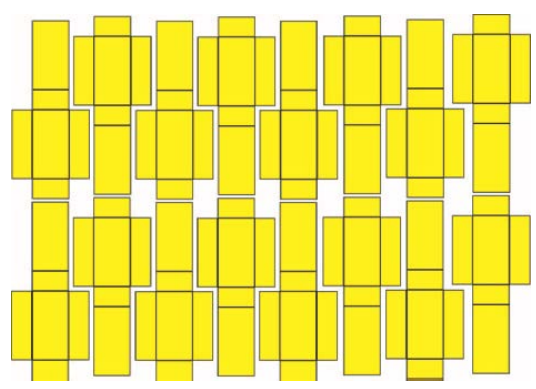

Gambar 2. Imposisi Sisip (S)

3. Imposisi gabung tidak sisip, yaitu sama seperti imposisi umum hanya saja dalam satu lembar kertas cetak tersebut bisa terdiri dari 2 hingga 3 jenis produk. Pemakaian imposisi ini hanya dapat dilakukan untuk produk yang menggunakan jenis dan gramatur kertas yang sama, pemakaian jenis tinta yang sama, serta menggunakan jenis coating yang sama. Kelemahan pada imposisi ini yaitu lebih dalam melakukan sortir, sehingga antara produk yang satu dengan produk yang lainnya lebih mudah tercampur.

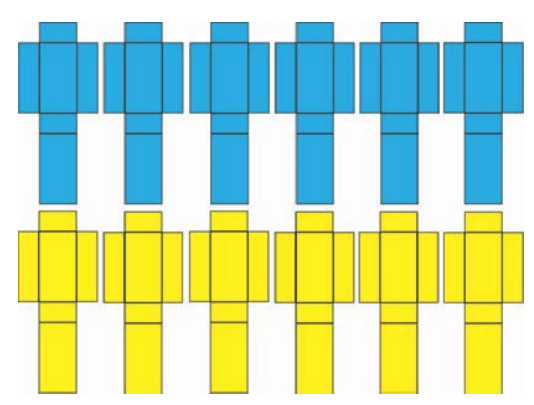

Gambar 3. Imposisi Gabung Tidak Sisip (GTS)

4. Imposisi gabung sisip yaitu gabungan antara imposisi sisip dan gabung. Sama halnya seperti imposisi gabung, imposisi sisip gabung hanya dapat dilakukan untuk produk yang menggunakan jenis dan gramatur kertas yang sama, pemakaian tinta yang sama, serta menggunakan jenis coating yang sama. Pemakaian imposisi ini lebih beresiko karena ketika proses cetak dan proses die cutting, imposisi jenis ini lebih sulit untuk mencapai register. Selain itu pada proses sortir pun lebih mudah tercampur antara produk satu dengan produk yang lai

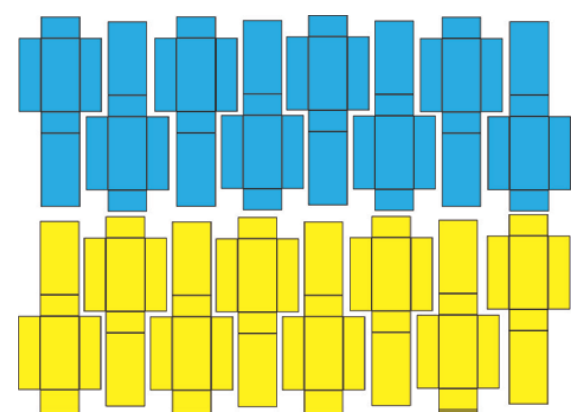

Gambar 4. Imposisi Gabung Sisip (GS) 
Penelitian ini bermanfaat agar perusahaan dapat mengoptimalkan ketersediaan kertas tanpa mengurangi fungsi kemasan. Fungsi kemasan karton agar dapat berdiri dengan tegak sehingga harus tepat arah seratnya. Desain imposisi kertas pada proses pra cetak dan dipalikasikan pada produk harus tepat sesuai dengan arah serat kertas namun mendapatkan kondisi kemasan yang berkualitas baik dan jumlah yang optimal dan meminimalisasi waste.

\section{METODE PENELITIAN}

Metode yang digunakan dalam penelitian ini adalah perhitungan kalkulasi biaya dengan membandingkan 4 (empat) macam imposisi menggunakan kertas dupleks 350 gram dengan ukuran plano 90 x 120 cmdengan memperhatikan waste yang dihasilkan tiap imposisi.

Adapun langkah penelitian sebagai berikut:

1. Persiapan, pengambilan sampel menggunakan data bulan januari hingga desember tahun 2016. Oplah yang digunakan adalah 10.000 produk.

2. Aplikasi variasi imposisi yang digunakan, antara lain: Imposisi Tidak Sisip (TS), Sisip (S), Gabung Tidak Sisip (GTS) dan Gabung Sisip (GS).

3. Perhitungan harga pokok kalkulasi menggunakan rumus yang telah ditentukan

4. Analisis terhadap hasil penelitian yang telah dilakukan

Urutan langkah penelitian diilustrasikan dalam gambar diagram alir berikut ini:

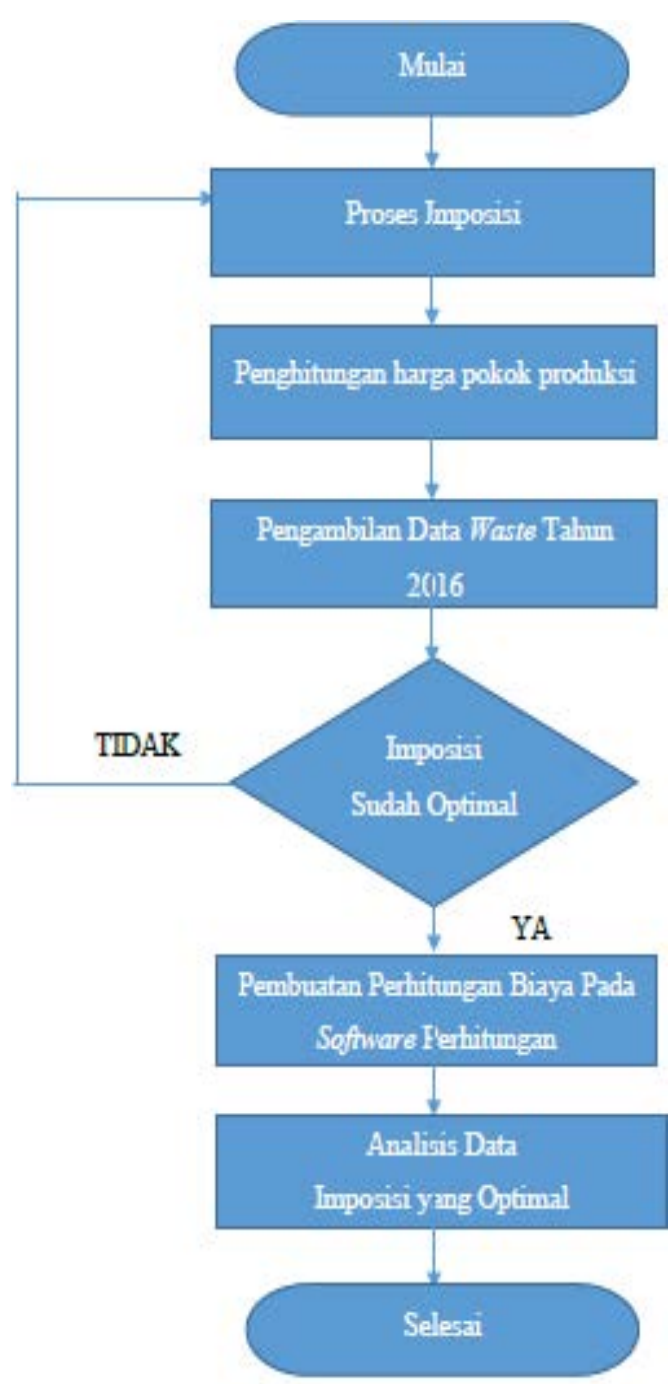

Gambar 5. Diagram Alir Penelitian

\section{HASIL dan PEMBAHASAN Pembahasan}

Biaya material kemasan menggunakan kertas dupleks 350 gr dengan ukuran plano 90 x $120 \mathrm{~cm}$. Analisis ini dilihat dari segi harga dan waste yang dihasilkn oleh masingmasing jenis imposisi.

\section{Perhitungan Harga}

Data yang digunakan dalam perhitungan harga, antara lain:

1. Biaya penggunaan mesin

2. Biaya kertas: jenis kertas, gramatur kertas, jumlah warna pada kemasan, serta ukuran plano yang digunakan. Selain itu penentuan kertas insheet, yaitu 500 lembar kertas.

3. Biaya pelat dan tinta. 
4. Biaya finishing: pisau, cairan 8.987.055,329, Rp. 4.899.850,641, dan varnish dan packing.

\section{Harga} Rp.4.996.537,748.

Pada ukuran 90 x $120 \mathrm{~cm}$ pada oplah 10.000 dengan imposisi gabung tidak sisip (GTS), besar biaya material pada oplah 10.000 yaitu Rp.10.120.540,75. Sedangkan biaya material pada imposisi gabung sisip (GS), tidak sisip (TS), dan imposisi sisip (S)adalah Rp.

Tabel 2. Harga per kemasan

\begin{tabular}{|l|l|l|l|r|}
\hline $\begin{array}{l}\text { Jenis } \\
\text { Imposisi }\end{array}$ & Oplah & $\begin{array}{l}\text { Harga } \\
\text { Material }\end{array}$ & $\begin{array}{l}\text { Harga } \\
\text { Persiapan } \\
\text { \& Produksi }\end{array}$ & $\begin{array}{l}\text { Harga Per } \\
\text { Kemasan }\end{array}$ \\
\hline TS & 10.000 & 4899850,641 & 1.707 .414 & 727 \\
\hline S & 10.000 & 4996537,748 & 1.742 .323 & 741 \\
\hline GTS & 10.000 & 10120540,75 & 2.990 .872 & 361 \\
\hline GS & 10.000 & 8987055,329 & 2.941 .508 & 328 \\
\hline
\end{tabular}

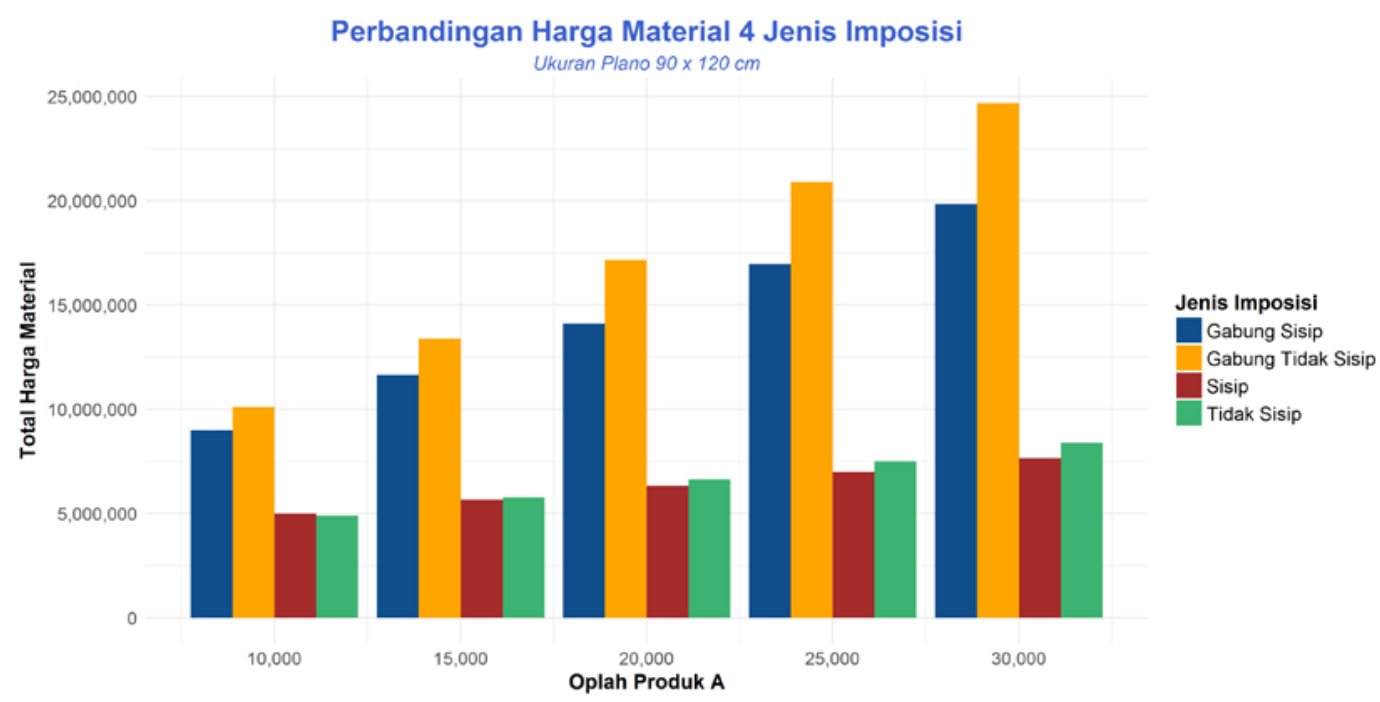

Gambar 6. Grafik perbandingan harga masing-masing jenis imposisi 


\section{Waste yang dihasilkan}

Adapun perhitungan besar waste menggunakan rumus sebagai berikut:

Waste $=($ Jumlah Pesanan + Insheet $)-$ Jumlah Finish

Dan persentase waste menggunakan rumus:

$$
\% \text { Waste }=\frac{\text { Jumlah } \text { waste }}{\text { oplah }+ \text { insheet }} \times 100 \%
$$

Berdasarkan rumus di atas maka waste yang dihasilkan pada 4 variasi imposisi terlihat dalam Gambar 7. Grafik Prosentase Sampah Tahun 2016. Berdasarkan data tahun 2016 maka imposisi jenis gabung sisip (GS) mendapat jumlah pesanan terendah yaitu5.558.597denganpersentasewaste 1 8,85\%.Pada imposisi jenis gabung tidak sisip (GTS) mendapat jumlah imposisi 12.376.491 dengan seluruh persentase waste33,44\%. Pada imposisi jenis sisip (S) jumlah pesanan mencapai 35.036.221 dengan persentase waste $14,08 \%$. Pada imposisi jenis tidak sisip (TS) jumlah pesanan 44.959.338 dengan persentase waste10,08\%.

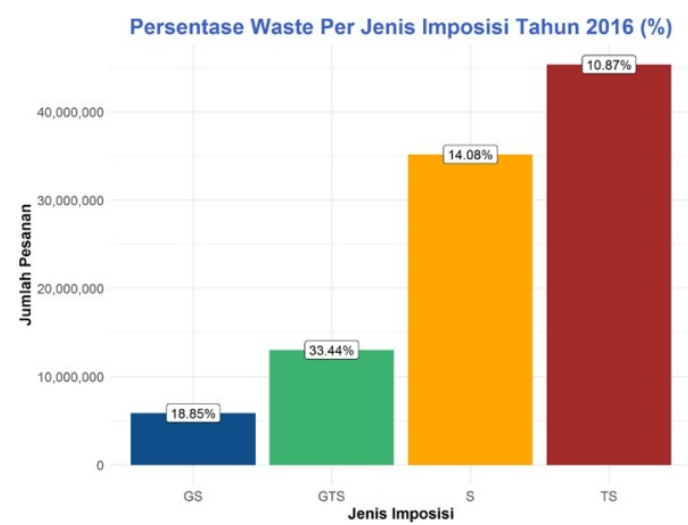

Gambar 7. Grafik prosentase sampah tahun 2016

Sehingga dapat terlihat pada Gambar grafik di atas, bahwa jenis imposisi yang memiliki presentase wasteterkecil adalah imposisi jenis tidak sisip (TS). Hal ini dikarenakanpadaimposisijenistidaksisip
(TS) hanya terdiri dari satu jenis produk dan jarak antar desain pada imposisi tersebut cukup jauh, sehingga pada proses cetak ataupun pada proses pond, kemasan yang menggunakan imposisi tersebut lebih mudah dalam mencapai register. Sedangkan jenis imposisi yang memiliki presentase waste terbesar adalah imposisi jenis gabung tidak $\operatorname{sisip}(\mathrm{GTS})$.

\section{KESIMPULAN}

Berdasarkan penelitian yang telah dilakukan maka dapat disimpulkan bahwa dari keempat variasi imposisi, untuk imposisi TS menghasilkan waste paling rendah sebesar $10,08 \%$. Hal ini kemungkinan dikarenakan pada imposisi ini terdapat jarak yang memudahkan dalam mencari register sehingga baik untuk proses cetak dan finishing. Sedang yang memiliki harga paling murah adalah imposisi GS, yaitu sebesar Rp. 328,00 per kemasan dengan oplah 10.000 .

\section{UCAPAN TERIMAKASIH}

Ucapan terima kasih kepada PT Kartika Naya yang telah memberikan kesempatan untuk observasi dan pengambilan data. Dan terimakasih kepada seluruh civitas akademik terutama Jurusan Teknik Grafika dan Penerbitan yang telah memberikan dukungan sehingga penelitian ini dapat terselesaikan dengan baik.

\section{DAFTAR PUSTAKA}

[1] Assauri, Sofjan. 1993. Manajemen Produksi dan Operasi. Fakultas Ekonomi Universitas Indonesia:Jakarta. 
[2] Budi santoso, Totok. 2000. Akutansi Manajerial. Jakarta:Salemba Empat.

[3] Enterprise, Jubilee. 2013. Tip Trik Formula Excel Terapan. PT Elex Media Komputindo:Yogyakarta.

[4] Scheder, Georg. 1977. Perihal Cetak Mencetak. Kanisius:Yogyakarta.

[5] Indonesian student. 2017. "Pengertian Kemasan Menurut Para Ahli”. Melalui http://www.indonesiastudent.com/p engertian-kemasan-menurut-paraahli. Diakses pada tanggal 3 April 2017.

[6] Kotler, Philip. 2003. Marketing Management Thirteenth Edition, terjemah oleh Bob Sabran, 2008. Erlangga: Jakarta.

[7] Mardjuki, Sentot. 2000. Kalkulasi Produksi Grafika dan Penerbitan. Humaniora Utama Press (HUP): Bandung

[8] Muryeti. 2009. Modul Ilmu Bahan Grafika 2. Politeknik Negeri Jakarta: Depok.

[9] Muryeti. 2008. Modul Ilmu Bahan Grafika 1. Politeknik Negeri Jakarta: Depok.

[10] Wasono, Antonius Bowo. 2013. Kalkulasi Grafika 2. Direktorat Pembinaan Sekolah Menengah Kejuruan: Bandung.

[11] Wasono, Antonius Bowo. 2008. Teknik Grafika dan Industri Grafika. Direktorat Pembinaan Sekolah Menengah Kejuruan: Bandung. 
Endang Yuniarti dkk, Pengaruh Imposisi Desain.... 